\title{
The Role of Intercultural Communication Competence in Iranian EFL Learners' Demotivation: An Examination of the Predicting Causes
}

\author{
Shabnam Kurosh \\ English Language Department, Bonab Branch, Islamic Azad University, Bonab, Iran \\ Davud Kuhi \\ English Language Department, Maragheh Branch, Islamic Azad University, Maragheh, Iran
}

\begin{abstract}
Preparing effective language learners who are ready to engage with speakers from different linguistic and cultural backgrounds and to become internationally competent is a significant and challenging task. It is expected that language teaching programs need to provide the opportunity for learners to develop intercultural competency and learner beliefs through raising awareness about intercultural differences. Therefore, the instructional experience is prerequisite in preparing learners to become aware and supporter of the cross-cultural issues that can either facilitate or hinder learners' achievement. This study intends to explore the relationship between intercultural competence of the learners and their experienced degree of demotivation as expressed by them at the university level. Intercultural competence was operationalized as a multidimensional notion comprising the communication effectiveness, adaptation, social integration, knowledge of the target culture, and language competence. Findings of regression analysis highlighted that only the social integration and adaptation components could predict the degree of demotivation. Additionally, the correlation results revealed a strong relationship between the language competence and communication effectiveness components of intercultural competence. According to the obtained findings, the possible clarifications for the contribution of intercultural competence components to the demotivation of learners were elaborated.
\end{abstract}

Index Terms - intercultural communication competence, intercultural efficiency, social integration, adaptation, demotivation

\section{INTRODUCTION}

In today's world, individuals pay a great deal of attention and time to successful communication across cultures with other individuals and institutes around the world (Schwarzenthal, Juang, Schachner, van de Vijver, 2017). Intercultural communication forms the way people welcome the change, deliver messages across borders and cultures, and revisit the principal aspects of time and space. As Byram (1997) mentions, intercultural competence is "the ability to see relationships between different cultures - both internal and external to a society - and to mediate, that is interpret each in terms of the other, either for themselves or for other people" (p. 29). It also comprises the ability to critically or analytically understand that one's "own and other cultures"” perspective is culturally identified rather than inherent. In the case of countries where there are not opportunities for learners of the target language to speak that language outside the classroom context, resources that help them to be exposed to the target culture and language are of special importance and interest (Mascadri, Brownlee, Walker \& Alford, 2017). The amount of the increase and improvement in the appropriate learning of the language and the reduction of possible culture shock and demotivation when encountered with the target culture are important issues.

The decreasing motivation and learning patterns are usually accompanied with shifts in learners' developmental and social processes. Developmental factors comprise modifications in the physiological, physical, emotional, and cognitive processes; for example, learners' experience of youth and attainment of more complicated emotional and cognitive processes (Sigelman \& Rider, 2009). Developed cognitive capabilities permit learners to process multifaceted emotions and understandings of the world and apply the enlightening, yet complicated and, at times, controversial feedback from teachers, parents, peers, and the broader community (Sigelman \& Rider, 2009). Learners' advanced cognitive processes and their reception of several perspectives might lead to a genuine and correct understanding of their abilities (Wigfield, Eccles, Yoon, Harold, Arbreton, \& Freedman-Doan, 1997), as a result the decreasing optimism and motivation compared to younger learners. In contrast to this, developed cognitive processes might also imply that learners are more "active physically, emotionally and intellectually" with the eagerness to gain awareness about differences, controversies and a sense of agency and autonomy (Hargreaves, Earl, \& Ryan, 1996, p. 136). Consequently, learning environments 
that correspond with learners' learning needs keep them engaged and motivated to learn (Eccles, Midgley, Wigfield, Buchanan, \& Reuman, 1993), and environments that fail to provide such a support might lead to disappointment.

With respect to the significance of a supportive environment and a need to highlight and signify the linguistic as well as the cultural issues of a target language, the present study was carried out to investigate the role that intercultural communicative competence (ICC) components play in the occurrence and management of learning demotivation, the role that seems to be unclear and under investigated.

\section{REVIEW OF THE LITERATURE}

Since there have been numerous definitions for intercultural competence, Bennet, and Wiseman (as cited in Guerro, 2008) intended to shed light on the vagueness of ICC definitions by distinguishing between intercultural sensitivity and intercultural competence. From their perspective, intercultural sensitivity is "the ability to discriminate and experience relevant cultural differences" whereas intercultural competence is "the ability to think and act in interculturally appropriate ways" (p. 422). The distinction precludes to the difference between knowing and performing in interculturally competent ways. Accordingly, Bennett (1993) specifies intercultural sensitivity as the world perspectives that identify how individuals respond to cultural varieties; it is presumed that these responses can be expected since individuals learn to become more proficient intercultural communicators.

Bennett's (1993) Developmental Model of Intercultural Sensitivity (DMIS) explains the reactions of people to cultural differences in predictable ways to became more competent intercultural communicators. The proposed model consists of six developmental stages: denial, defence, minimization, acceptance, adaptation, and integration. Each of the stages is discussed as follows. Denial stage is the first stage in which the person denies the target culture. The second stage, namely defence, is the stage in which the person defends his or her culture against the target culture. In the minimization stage, the person tends to make the differences existing among the two cultures minimum. In the fourth stage, the person begins to accept the target culture and becomes much closer to the target people and community. And, in the adaptation stage the person sees the differences minimally and tries to adapt to the target culture. Finally, the last stage demonstrates the complete integration of the person in the social community of the target culture. Wiseman (2003) explains that, intercultural competence "involves the knowledge, motivation, and skills to interact effectively and appropriately with members of different cultures" (p. 194).

To best capture the significance of ICC, different models of intercultural competence have been suggested by numerous scholars (e.g., Porter \& Samovar, 1976; Hammer, Gudykunst, \& Wiseman, 1978; Byram, 1997). One of the most influential models for intercultural competence, for instance is the Intercultural Competence Model proposed by Byram (1997) which is applied in foreign language classrooms widely. The proposed model consists of four distinct but interdependent components. The first one is the skill component which itself consists of the skills of discovery and interaction, and skills of interpreting and relating. The remaining two components are knowledge and attitude. In an educational setting, "the interplay of these first three components ideally should lead to the fourth component, namely the critical cultural awareness or an evaluative orientation (Byram, p. 43) toward the examination of difference". Therefore, the learners' appraisal of the conditions is made explicit and the new evaluative inclination toward differences brings about a readiness for political engagement.

Moreover, there is Porter and Samovar's (1976) classification of effective intercultural communication which is another model for intercultural competence. Their classification consists of eight cultural variables that account for effective intercultural communication, including attitudes, social organization, patterns of thought, roles and role expectations, language, space, time, and nonverbal expression.

In another treatment of ICC, Hammer et al. (1978) suggested the intercultural adjustment model when investigating intercultural communication competence. Hammer et al. (1978) analyzed 24 personal abilities considered important in intercultural situations. The factor analysis identified three basic qualities: the capability to handle psychological anxiety, the ability to interact appropriately, and the ability to generate interpersonal relationships.

Other examinations of ICC and intercultural effectiveness have determined other communication constructs consisting of communication skills, empathy, knowledge of the target culture, and language competence (Hannigan, 1990; Kim, 1991; He, Lundgren, \& Pynes, 2017; Searle \& Ward, 1990; Ward \& Searle, 1991).

This review of the intercultural communication competence provides six main components of communication skills, knowledge of the target culture, language competence, adaptation, communication effectiveness, and social integration.

Intercultural Effectiveness and Demotivation

Motivation is acknowledged as a principal determinant of success in language learning. Second language researchers and teachers have traditionally focused on the positive effects of motivation that increase interest and facilitate language learning (e.g., Masgoret \& Gardner, 2003; Dornyie, 1994a, 1994b; Dörnyei \& Clement, 2001; Dörnyei, 2003). In fact, the rate and success of language learning are influenced by motivation. Dörnyei (2009) believes that motivation provides "primary impetus to initiate second/foreign language learning and later the driving force to sustain the long and often tedious learning process" (p. 16). Without adequate motivation, as a driving and moving force, it is very difficult to learn a second language. It is safe to say that motivation can "make up for considerable deficiencies both in language aptitude and learning conditions" (Dörnyei, 1998, p.117).

Recently, some researchers have shifted their attention to demotivation which is "another side of motivation" (e.g., 
Falout \& Maruyama, 2004; Kikuchi, 2009; Sakai \& Kikuchi, 2009). In contrast to the positive influence of motivation, demotivation has negative effects on language learning processes and outcomes. When learners are demotivated, the language learning target becomes more challenging and less enjoyable; therefore, the accomplishment of predicted learning outcomes gets very difficult (Hattie \& Yates, 2014; Peterson, Brown, \& Irving, 2010). Furthermore, students' demotivation might lead to amotivation which refers to the complete absence of any motivation and interest in learning target language (Falout et al., 2009). Amotivated language learners fail to learn second language because they consider themselves to be incompetent to acquire the language; therefore, their success in language learning is impossible (Falout et al., 2009).

Considering the above discussion, it can be argued that students' demotivation is a significant language learning problem that needs to be specifically addressed in the second language learning. In fact, this phenomenon needs to be explored in-depth in order to identify its common causes and overcome its negative effects. Therefore, the present study is conducted in order to investigate and identify the main sources of students' demotivation in second language learning from an intercultural perspective since learners' intercultural experience and their attitudes can potentially impact their successful learning (Krajewski, 2011; Jon, 2013; Barker \& Mak, 2013). The study attempts to provide answer to the following research questions:

1. What is the contribution of intercultural communication competence components to the amount of demotivation as expressed by Iranian EFL learners?

2. How do the intercultural communication competence components interrelate?

\section{Methodology}

Participants

The participants of this study $(\mathrm{N}=48)$ included male and female university learners majoring in language teaching. The average age was 24 years with a range of 20 to 28 years. They were all learning English as a foreign language.

Instruments

The 35-item demotivation questionnaire developed by Sakai and Kikuchi (2009) was employed in this study. The questionnaire included three sections: questions about learners' demographic information, questions about demotivating factors, and open-ended questions about respondents' experience of being motivated and demotivated. The questionnaire was a 5-point Likert type scale which applied: 1) not true for me, 2) not true for me so much, 3) cannot say either "true" or "not true," 4) true for me to some degree, and 5) true for me. Therefore, the higher the score, the greater the demotivation is. And, the open-ended section included two questions: "Write your experiences about situations in which your motivation to study English was heightened" and "Write your experiences regarding times when your motivation to study English was decreased." The reliability index of the questionnaire was estimated by means of Cronbach alpha and turned out to be .83 for this study.

To investigate the intercultural communicative competence of the learners, Redmond and Bunyi's questionnaire was employed. The scale consisted of the following constructs: knowledge of host culture (4 items), language competence (3 items), communication effectiveness (6 items), adaptation ( 7 items), and social integration (6 items). The reliability of the scale is found as a Cronbach alpha of .89 for the present study.

Procedure

The questionnaires were emailed to the participants in March 2014. It took 20 to 30 minutes to complete the questionnaires. Afterwards, the data were imported to the SPSS software (version 21) for the analyses.

\section{RESULTS}

Prior to the conduction of multiple regression analyses, conditions of independency, normality, and linearity were tested and the scatter plots were depicted to corroborate that these conditions were met. In analyzing partial regression coefficients, the probability of multicollinearity between the independent variables needed to be examined. However, there were low values of Variance Inflation Factor (VIF), referring to the lack of serious multicollinearity.

Firstly, table 1 shows the results of multiple linear regression analysis for the ICC components as independent variables and demotivation as the dependent variable.

TABLE 1.

RESUlTS OF MULTIPLE LINEAR REGRESSION ANALYSIS OF ICC AND DEMOTIVATION

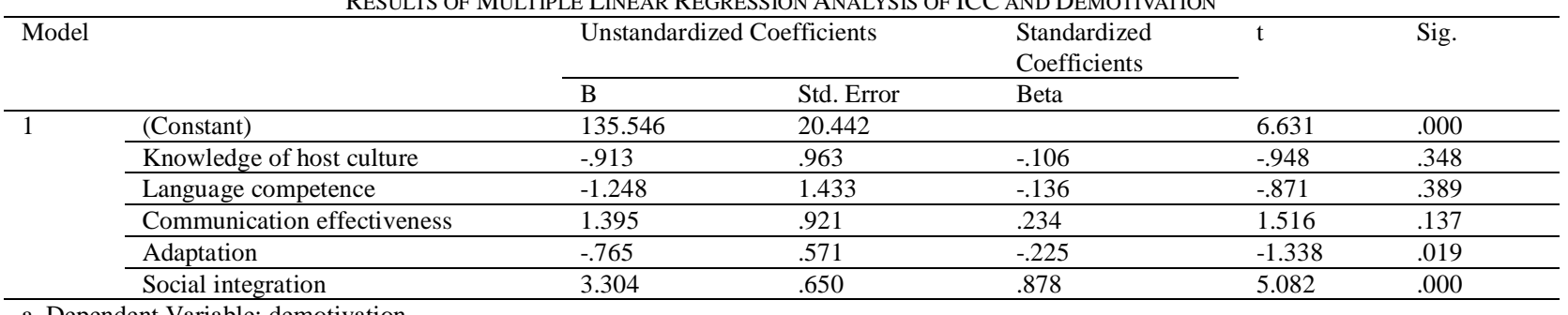

a. Dependent Variable: demotivation 
As the above table shows, the adaptation and social integration components of ICC had statistically significant ( $\mathrm{p}<$ 0.05) impact on the demotivation of the participants. In other words, the above variables could better predict the variation of the dependent variable such that the low levels of adaptation and high levels of social integration led to demotivation. Altogether, the above mentioned independent variables could predict the 46 percent of the variation in the dependent variable.

In order to examine and provide an answer to the second research question of the study, a Pearson correlation coefficient was run. The results are reported below. Firstly, table 2 shows the descriptive statistics results and then table 3 indicates the correlation coefficient results.

TABLE 2.

DESCRIPTIVE STATISTICS OF ICC COMPONENTS' RELATION

\begin{tabular}{llll}
\hline & Mean & Std. Deviation & $\mathrm{N}$ \\
\hline Knowledge of host culture & 13.1875 & 3.65918 & 48 \\
\hline Language competence & 9.7292 & 3.42543 & 48 \\
\hline Communication effectiveness & 18.6042 & 5.28643 & 48 \\
\hline Adaptation & 13.8958 & 9.26499 & 48 \\
\hline Social integration & 13.8542 & 8.36657 & 48 \\
\hline
\end{tabular}

TABLE 3.

CORRELATION RESULTS OF ICC COMPONENTS' RELATION

\begin{tabular}{|c|c|c|c|c|c|c|}
\hline & & $\begin{array}{l}\text { Knowledge of } \\
\text { host culture }\end{array}$ & $\begin{array}{l}\text { Language } \\
\text { competence }\end{array}$ & $\begin{array}{l}\text { Communication } \\
\text { effectiveness }\end{array}$ & adaptation & $\begin{array}{l}\text { Social } \\
\text { integration }\end{array}$ \\
\hline \multirow{3}{*}{$\begin{array}{l}\text { Knowledge of host } \\
\text { culture }\end{array}$} & Pearson Correlation & 1 & -.001 & -.019 & -.077 & -.253 \\
\hline & Sig. (2-tailed) & & .995 & .897 & .605 & .082 \\
\hline & $\mathrm{N}$ & 48 & 48 & 48 & 48 & 48 \\
\hline \multirow[t]{3}{*}{ Language competence } & Pearson Correlation & -.001 & 1 & $.707^{* *}$ & -.030 & -.145 \\
\hline & Sig. (2-tailed) & .995 & & .000 & .837 & .326 \\
\hline & $\mathrm{N}$ & 48 & 48 & 48 & 48 & 48 \\
\hline \multirow{3}{*}{$\begin{array}{l}\text { Communication } \\
\text { effectiveness }\end{array}$} & Pearson Correlation & -.019 & $.707^{* *}$ & 1 & -.140 & -.118 \\
\hline & Sig. (2-tailed) & .897 & .000 & & .343 & .424 \\
\hline & $\mathrm{N}$ & 48 & 48 & 48 & 48 & 48 \\
\hline \multirow[t]{3}{*}{ Adaptation } & Pearson Correlation & -.077 & -.030 & -.140 & 1 & $.747^{* *}$ \\
\hline & Sig. (2-tailed) & .605 & .837 & .343 & & .000 \\
\hline & $\mathrm{N}$ & 48 & 48 & 48 & 48 & 48 \\
\hline \multirow[t]{3}{*}{ Social integration } & Pearson Correlation & -.253 & -.145 & -.118 & $.747^{* * *}$ & 1 \\
\hline & Sig. (2-tailed) & .082 & .326 & .424 & .000 & \\
\hline & $\mathrm{N}$ & 48 & 48 & 48 & 48 & 48 \\
\hline
\end{tabular}

**. Correlation is significant at the 0.01 level (2-tailed).

As it is obvious from table 3, the significant correlation index belongs to the relationship between language competence and communication effectiveness. Put another way, there was a strong, direct, and positive relationship ( $\mathrm{r}=$ 0.70) between these ICC components (Cohen, 1988). The other components were not correlated with each other.

\section{Discussion}

From among the ICC qualities, only the adaptation and social integration components were found to be significant contributors of the regression equation and could predict $46 \%$ of the variation in the amount of demotivation. This result has the implication that the amount of demotivation experienced by EFL learners is mostly irrelevant of their communication skills or cultural knowledge. Demotivation is clearly felt regardless of the familiarity or communicative competence of the foreign language learners.

The surprising result was that the stronger the amount of social integration a learner expressed, the more likely they were exposed to demotivation. The possible explanation for this relationship would be that an attempt for integration can in fact lead to higher levels of stress a learner experiences. A strong integrator would be more conscious of the distinctions between his/her culture and the one being learned. This consciousness might contribute to a higher amount of demotivation that was felt by those who are more inattentive to cultural distinctions. On the other hand, it has been put forward that being anxious and demotivated actually leads to better adaptation and assimilation through the procedure of stress-adaptation-growth (Kim \& Ruben, 1988). Social integration could lead to efficient adaptation by boosting the amount of demotivation experienced leading to adaptation and augmentation.

Results of correlation coefficient showed that except for language competence and communication effectiveness, all the other ICC components were not significantly correlated. This finding mans that Iranian EFL learners found the language competence and communication effectiveness components as the ones that are critical to the cultural adaptation process (Okazaki-Luff, 1991). In addition, communication effectiveness which refers to the learners' ability to interact with target people, to handle communication misunderstandings, and to empathize with and sense the feelings of target people is identified as both a predictor of intercultural competence (Ruben \& Kealey, 1979), and an outcome (Imahori \& Lanigan, 1989).

An analysis of the participants' responses to the open-ended questions determined their sources of demotivation and 
motivation in the classroom. Respondents agreed that the materials, learning content, and equipment were sources causing lower motivation. In other words, the existence of uninteresting and attractive materials, the exclusive focus on academic skills of reading, writing, and grammar at the expense of other skills and abilities were found to be sources of demotivation. In fact, this finding is consistent with the results of quantitative analyses where learners' identified the linguistic competence and communication effectiveness as the fundamental components of ICC. Furthermore, the results indicated that the lack of learning facilities, such as videos, tapes, DVDs, CDs, and computers, were also demotivating. This result of the present study supports the findings of the past research which have connected the learners' demotivation to the learning materials and contents (e.g., Dörnyei, 1998; Falout \& Maruyama, 2004; Kikuchi \& Sakai, 2009). The findings by Sakai and Kikuchi (2009) revealed that learning subjects and materials were the one of the most prominent reasons of demotivation for language learners. In addition, results of the present study are consistent with those of prior research on language learning demotivation which have considered inadequate school facilities as one of the major demotivating factor (e.g., Dörnyei, 1998; Kikuchi \& Sakai, 2009). To sum up, there needs to be enough attention paid to the teachers and learners appreciation of the intercultural issues that can bring about demotivation in learners or burnout in teachers (Sadeghi \& Khezrlou, 2014; 2016). The latter is an open question that warrants further investigation.

\section{REFERENCES}

[1] Barker, M. C., \& Mak, A. S. (2013). From classroom to boardroom and ward. Journal of Studies in International Education, 17(5), 573-589.

[2] Bennett, M. J. (1993). Towards ethnorelativism: A developmental model of intercultural sensitivity (revised). In R. M. Paige (Ed.), Education for the intercultural experience (pp. 56-78). Yarmouth, Me: Intercultural Press.

[3] Byram, M. (1997). Teaching and assessing intercultural communicative competence. Clevedon: Multilingual Matters.

[4] Dörnyei, Z. (1994a). Motivation and motivating in the foreign language classroom. The Modern Language Journal, 78, 273-284.

[5] Dörnyei, Z. (1994b). Understanding L2 motivation: On with the challenge. The Modern Language Journal, 78(4), 515-523.

[6] Dörnyei, Z. (1998). Motivation in second and foreign language learning. Language Teaching, 31, 117-135.

[7] Dörnyei, Z. (2003). Attitudes, orientations, and motivations in language learning: Advances in theory, research, and applications. In Z. Dörnyei (Ed.), Attitudes, orientations and motivations in language learning (pp. 3-32). Oxford: Blackwell

[8] Dörnyei, Z. (2009). Motivation and the vision of knowing a second language. In B. Beaven (Ed.), IATEFL 2008: Exeter conference selections (pp. 16-22). Canterbury: IATEFL.

[9] Dörnyei, Z., \& Clément, R. (2001). Motivational characteristics of learning different target languages: Results of a nationwide survey. In Z. Dörnyei \& R. Schmidt (Eds.), Motivation and second language acquisition (pp. 399-432). Honolulu, HI: University of Hawaii Press.

[10] Eccles, J. S., Midgley, C., Wigfield, A., Buchanan, C. M., Reuman, D., Flanagan, C. (1993). Development during adolescence: The impact of stage-environment fit on young adolescents' experiences in schools and in families. American Psychologist, 48(2), 90-101.

[11] Falout, J., Elwood, J., \& Hood, M. (2009). Demotivation: Affective states and learning outcomes. System, 37, 403-417.

[12] Falout, J., \& Maruyama, M. (2004). A comparative study of proficiency and learner demotivation. The Language Teacher, 28(8), 3-9.

[13] Guerro, E. A. (2008). From intercultural sensitivity to intercultural competence: An intercultural approach to integrate language and culture in the Spanish class. Retrieved March 3, 2014, from http://www-interculturalsensitivity.com.

[14] Hammer, M., Gudykunst, W., \& Wiseman, R. (1978). Dimensions of intercultural effectiveness: An exploratory study. International Journal of Intercultural Relations, 2, 282-393.

[15] Hanningan, T. P. (1990). Traits, attitudes, and skills that are related to inter-cultural effectiveness and their implications for cross-cultural training: A review of the literature. International Journal of Intercultural Relations, 14, 89-111.

[16] Hargreaves, A., Earl, L., \& Ryan, J. (1996). Schooling for change: Reinventing education for early adolescents. London: Falmer Press.

[17] Hattie, J., \& Yates, G. (2014). Visible learning and the science of how we learn. Oxon, United Kingdom: Routledge.

[18] He, Y., Lundgren, K., \& Pynes, P. (2017). Impact of short-term study abroad program: Inservice teachers' development of intercultural competence and pedagogical beliefs. Teaching and Teacher Education, 66, 147-157.

[19] Imahori, T. T., \& Lanigan, M. L. (1989). Relational model of intercultural communication competence. International Journal of Intercultural Relations, 13, 269-286.

[20] Jon, J-E. (2013). Realizing internationalization at home in Korean higher education: Promoting domestic students' interaction with international students and intercultural competence. Journal of Studies in International Education, 17(4), 455-470.

[21] Kikuchi, K. (2009). Listening to our learners' voices: What demotivates Japanese high school students? Language Teaching Research, 13(4), 453-471.

[22] Kim, Y. Y. (1991). Intercultural communication competence: A systems-theoretic view. In S. Ting-Toomey \& F. Kerzenny (Eds.), International and Intercultural Communication Annual (pp. 259-275). Newbury Park, CA: Sage.

[23] Kim, Y. Y., \& Ruben, B. D. (1988). Intercultural transformation: A systems theory. In Y. Y. Kim \& W. B. Gudykunst (Eds.), Theories in intercultural communication (pp. 299-321). Newbury Park, CA: Sage.

[24] Krajewski, S. (2011). Developing intercultural competence in multilingual and multicultural student groups. Journal of Research in International Education, 10(2), 137-153.

[25] Mascadri, J., Bownlee, J. L., Walker, S., \& Alford, J. (2017). Exploring intercultural competence through the lens of self-authorship. Early Years: An International Research Journal, 37, 217-234.

[26] Masgoret, A. M., \& Gardner, R. C. (2003). Attitudes, motivations, and second language learning: A meta-analysis of studies 
conducted by Gardner and associates. Language Learning, 53(1), 123-163.

[27] Okazaki-Luff, K. (1991). On the adjustment of Japanese sojourners: Beliefs, contentions, and empirical findings. International Journal of Intercultural Relations, 15, 85-102.

[28] Peterson, E. R., Brown, G., \& Irving, S. E. (2010). Secondary students' conceptions of learning and their relationships to achievement. Learning and Individual Differences, 20, 167-176.

[29] Porter, R. E., \& Samovar, L. A. (1994). An introduction to intercultural communication. In L. A. Samovar, \& R. E. Porter (Eds.), Intercultural communication: A reader (7th Ed.) (pp. 4-25). Belmont, CA: Wadsworth Publishing.

[30] Redmond, M. V., \& Bunyi, J. M. (1993). The relationship of intercultural communicative competence with stress and the handling of stress as reported by international students. International Journal of Intercultural Relations, 17, 235-254.

[31] Ruben, B. D., \& Kealey, D. J. (1979). Behavioral assessment of communication competency and the prediction of cross-cultural adaptation. International Journal of Intercultural Relations, 3, 15-48.

[32] Sadeghi, K., \& Khezrlou, S. (2014). Burnout among English language teachers in Iran: Do sociodemographic characteristics matter? Procedia- Social and Behavioral Sciences, 98, 1590-1598.

[33] Sadeghi, K., \& Khezrlou, S. (2016). The experience of burnout among English language teachers in Iran: Self and other determinants. Teacher Development, 20(5), 1-17.

[34] Sakai, H., \& Kikuchi, K. (2009). An analysis of demotivators in the EFL classroom. System, 37, 57-69.

[35] Schwarzenthal M., Juang L. P., Schachner M. K., van de Vijver, F. J. R., Handrick, A. (2017). From tolerance to understanding: Exploring the development of intercultural competence in multiethnic contexts from early to late adolescence. Journal of Community and Applied Social Psychology, 27, 388-399.

[36] Searle, W., \& Ward, C. (1990). The prediction of psychological and socio-cultural adjustment during cross-cultural transitions. International Journal of Intercultural Relations, 14, 449-464.

[37] Sigelman, C. K., \& Rider, E. A. (2009). Life-span human development. Belmont CA: Wadsworth Cengage Learning.

[38] Ward, C., \& Searle, W. (1991). The impact of value discrepancies and cultural identity on psychological and sociocultural adjustment of sojourners. International Journal of Intercultural Relations, 15, 209-225.

[39] Wigfield, A., Eccles, I. S., Yoon, K. S., Harold, R. D., Arbreton, A. A., \& Freedman-Doan, C. (1997). Change in children's competence beliefs and subjective task values across the elementary school years: A 3-year study. Journal of Educational Psychology, 89, 451-469.

[40] Wiseman, R. L. (2003). Intercultural communication competence. In W. B. Gudykunst (ed.), Cross-cultural and intercultural communication (pp. 191-208). Thousand Oaks: Sage.

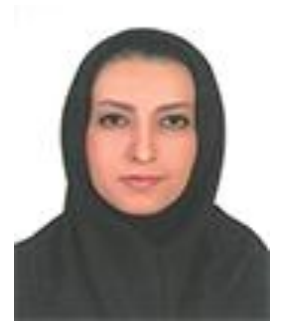

Shabnam Kurosh Khanshan was born in Urmia, 1983. She is currently PhD student in TEFL in Islamic Azad University (Bonab Branch), and got her MA from Tabriz, Iran, 2011. She is mainly interested in second language acquisition, psycholinguistics and discourse analysis. She has some publications in national and international journals.

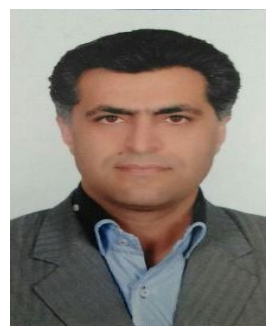

Davud Kuhi, Phd in applied linguistics, is a member of English language department in Islamic Azad University. He has researched extensively on the sociocultural dimensions of scientific and academic discourses. 